peroxide, inhibits rusting. He ignores the fact that there are other substances, such as potassium iodide, which immediately destroy hydrogen peroxide and yet do not inhibit the rusting of iron. Moreover, if Prof. Dunstan's assumption that substances which destroy hydrogen peroxide (which he regards as an essential initial product of rusting) inhibit rusting be accepted, it will be necessary to admit, contrary to the general experience of chemists, that the presence of a substance capable of removing one of the products of an action does not accelerate the action, but actually prevents it.

Prof. Dunstan does not say in what respects his experiments on the oxidation of iron have afforded results differing from my own, but I may remind him that only after repeated failures was I successful in bringing together iron, oxygen, and water, and in avoiding the presence of acid.

Central Technical College, February 22. GERALD T. MOODY.

The Valparaiso Earthquake, August $17,1906$.

Prof. Milne's note in Nature of February 21 raises an interesting question which can readily be answered the earthquake which preceded the Valparaiso shock originated under the North Pacific Ocean in about $30^{\circ} \mathrm{N}$. lat., $170^{\circ}$ E. long., at about oh. IIm. a.m. G.M.T., or $35^{\frac{1}{2}}$ minutes before the Chilian earthquake as recorded at Santiago. This position does not agree with the distance given in the note, but Prof. Milne, in correspondence, has informed me that this is in error, and the distance, as indicated by the Shide diagram, is $90^{\circ}$, which is in close accordance with my own determination of the distance.

It must be remembered that all attempts at deducins the distance of origin from a single seismogram are necessarily approximate, though the error will probably be within $5^{\circ}$ of arc, or about 350 miles, in the case of a great earthquake giving a complete record. The determination of the place of origin becomes easy when a sufficient number of records from widely separated localities are available, and these are at my disposal, for, seeing that the Chilian carthquake was likely to be an important one in connection with an investigation on which I was engaged, I wrote to a number of seismological stations the addresses of which were known to me, and met with a most generous response to $\mathrm{my}$ requests. Unfortunately, when the copies of seismograms came in it was evident that they recorded two earthquakes, of which the earlier was of unknown origin, the record of which in every case overlapped that of the Chilian one, and rendered the latter practically useless.

R. D. Oldham.

\section{Nomenclature of the Proteins.}

IN the current number of the Proceedings of the Chemical Society, the council has issued some valuable proposals for change in the nomenclature of the proteids and allied substances. While not venturing to criticise the majority of the recommendations, I notice a definition in the proposed subclass 5 which appears to me slightly inaccurate. The subclass in question reads as follows:-

"5. Sclero-proteins. This new word takes the place of the word albuminoid in the limited sense in which the majority of physiologists have been accustomed to use it. It includes such substances as gelatin and keratin; the prefix indicates the skeletal origin and often insoluble nature of its members."

Now, it seems to be a generally accepted view that gelatin does not exist ready-formed in nature, but results from the hydrolysis or hydration of collagens ( $v$. Allen's " Organic Analysis," vol. iv., and Cohnheim's "Chemie der Eiweisskörper"). Is not gelatin as much a product of protein hydrolysis as acid albumin or alkali-albumin for which the generic term meta-proteins is now proposed? Would it not, therefore, be preferable to reserve the term sclero-proteins, in its strictest sense, for the wholly insoluble products of animal-cell activity, such as chondrigen, ossein, sericin, and keratin, and class their hydrationproducts such as gelatin and silk-gelatin among the metaproteins?

The committee apparently sees no objection to including gelatose among the proteoses.

Bocking, Braintree, Essex, March 4

W. S. Gilltis.

NO. I949. VOL. 75$]$
Maximum Gravitational Attraction on a Solid.

CAN you tell or refer me to the solution of the following question :-

What will be the shape of a definite quantity of mass of given specific gravity in order to obtain maximum gravitational attraction at a point on its surface? I have tried various shapes of equal volume, including square and rectangular figures, hemisphere, sphere, and cones. For these shapes $\hat{I}$ found that the maximum attraction obtained at the centre of the base of a cone the apex angle of which was about forty degrees; no doubt the frustrum of such a cone would attract with greater force.

This question is no doubt of academical interest only, but the solution should be instructive from certain points of view.

Publication Bureau, General Electric Co., Schenectady, New York, U.S.A.

THE solid is one of revolution (evidently), and the attraction being a maximum is unaltered by shifting a small elementary ring of matter from one point to another of its bounding surface. If $d \mathrm{M}$ is the mass of a ring formed by the revolution of the point $r, \theta$, then the attraction is $d \mathrm{M} \cos \theta / r^{2}$. Hence the equation of the generating curve of the boundary is $\cos \theta / r^{2}=$ const., or $r^{2}=k^{2} \cos \theta$ say, or $\left(x^{2}+y^{2}\right)^{3}=k^{4} x^{2}$. The curve may be traced by drawing the circle $r=k \cos \theta$, and taking on each radius vector a mean proportional between that radius and $k$.

According to this result, the form of the bounding curve for a surface of revolution is the same as it would be for a plane lamina possessing the same property. The agreement can be justified by taking a thin slice through the axis of the solid. The matter contained in this slice must evidently be arranged in such a form as to give the maximum attraction independently of the remaining parts of the body.

G. H. BRYAN.

\section{A New Chemical Test for Strength in Wheat Flour.}

THE test described as new by Mr. Wood in Nature of February $2 \mathrm{r}$ has been in use in my laboratory during the past year, where it forms part of the regular routine tests applied to flour. While $\mathrm{I}$ am fully in agreement with Mr. Wood's view that the volume of carbon dioxide evolved by a mixture of yeast and flour under standard conditions is a measure of the sugar content of the flour together with other fermentable matter produced during the fermentative change, it is important not to lose sight of the influence exercised by the character of the gluten on the volume of the loaf. A rotten gluten when distended by too much gas will break, and the gas will escape from the dough. From this point of view the character of the gluten is clearly of fundamental importance, but, after all, the problem is one in which no smalt number of variables must be dealt with.

\section{E. Frankland Armstrong.}

\section{A Remarkable Lunar Halo, February 24.}

IN NATURE of May I, 1902 (vol. 1xvi., p. 5), a remarkable lunar halo was described as having been witnessed from the Yerkes Observatory on January 19, 1902. It consisted of an ordinary lunar halo, of $45^{\circ}$ or $50^{\circ}$ in diameter, and of a second ring approximately the same in size intersecting the first, and cutting exactly through the moon.

The same phenomenon was very clearly seen by myself and others at Pembroke Dock during the evening of Sunday, February 24, between 9 p.m. and ro p.m. The secondary ring appeared to be about a third as large again in diameter as the primary, and was situated approximately to the north-east of it. In both rings the brownish tinge of the edges and dark interiors were perceptible, though very much more strongly in the primary than in the secondary.

I should be glad to know whether any explanation has yet been advanced as to the optical formation of the secondary ring in the above rare phenomenon.

H. F. Hunt

7 Officers Row, Pembroke Dock, Wales, February 26 